\title{
Evaluating impacts of organizational intelligence in creating competitive strategy in companies producing powder coating
}

\author{
Somaye Nasiri ${ }^{a^{*}}$, Mojtaba Javidnia ${ }^{a}, Z_{i b a}$ Vahedi Anvar ${ }^{b}$ and Nahid golbabaee ${ }^{c}$
}

\begin{abstract}
${ }^{a}$ Department Of Management, Semnan Branch, Islamic Azad University, Semnan , Iran
${ }^{b}$ Department Of Management, Payam noor University, Garmsar, Iran

${ }^{c}$ Department Of Management, Payam noor University, tehran, Iran

C H R O N I C LE A B T T A C T

Article history:

Received October 20, 2012

Received in revised format

5 January 2013

Accepted 19 January 2013

Available online

January 202013

Keywords:

Organizational intelligence

Structural equation modeling

Value chain

Organizational intelligence (OI) plays an important role on creating competitive strategy. This paper measure the effect of OI differentiation through value chain of organizational activities. The proposed study is applied in companies, which are active in the field of producing powder coating. Literature and background of research was reviewed to compile theoretical framework of the research model and after conducting library studies and performing exploratory interviews, important factors influencing OI on various sectors of the organization were extracted. In the same direction, these components were assessed through survey research and questionnaire tool. The proposed study uses structural equation modeling is implemented to study the effects of various factors and the validity of relationship among components was confirmed through a conceptual model.
\end{abstract}

Competitive advantage value

chain

\section{Introduction}

During the past few years, there has been significant growth on emerging new technologies so that communities in general and markets in particular are after following tricks to ensure their survival in such turbulent and chaotic circumstances. The organizations should admit that philosophy of their lives is under significant changes and their survival does not necessarily mean that they could achieve continuous profitability and they need to take necessary steps in such competitive and dynamic market. Under such circumstances, companies may find it difficult to do their business activities based on traditional systems without considering new rules and regulations. Firms need to be comply with new rules of business game to compete with others. Therefore, taking advantage of new technologies such as business intelligence in business activities is a necessity. Organizational intelligence in today's complicated firms would be the outcome and combination of two active human and machine artificial intelligence.

*Corresponding author. Tel: +989122314016

E-mail addresses: s.nasiri2000@yahoo.com (S. Nasiri) 
There is no doubt that managers have to apply all mentioned movements for dynamicity and boosting efficiency of their organization.

Albrecht (2002; 2003) offered a model of organizational intelligence with seven dimensions, including: 1- Strategic Vision, 2- Shared Fate, 3- Appetite for Change, 4- Alignment and Congruence, 5- Spirit, 6- Knowledge Deployment and 7- Performance Pressure. These seven components are considered as criteria in this study. When organizational intelligence processes are executed purposefully and systematically within organizations, its dramatic effects can be considered in creating competitive advantage in different sectors of any organization. We need to identify the results of using these plans in different sectors of the organization precisely to pose necessity of implementation of plans for organizational intelligence in organizations. If tangible specifications and simplicity of competitive advantage is incorporated, the organizational capability will be also increased, accordingly. However, if a company is supported with innovative-based organizational culture, it is possible to take advantage of its paramount feature smartly and promote its advantage suitably. In addition, the firm can create new advantage before rival companies attained the necessary advantage.

\section{Research Questions}

This study looks for the solution of the following questions,

1. What is the impact of organizational intelligence on value chain of activities of firms active in powder coating industry?

2. Is there any significant relationship between organizational intelligence and development of professional skills of manpower?

3. Is there any significant relationship between organizational intelligence and innovation in offering services and products?

4. Is there any significant relationship between organizational intelligence and improvement of management of relationship with customers?

5. Is there any significant relationship between organizational intelligence and development of products and services market?

6. What is the effect of organizational intelligence on the development of professional skills of manpower?

7. What is the effect of organizational intelligence on the innovation in offering services and products?

8. What is the effect of organizational intelligence on increasing customers' satisfaction from services?

\section{Literature Review}

\subsection{Organizational Intelligence}

There are various opinions from different perspectives on the organizational intelligence. Some researchers used business intelligence instead of organizational intelligence (Khanzadeh, 2007). Business intelligence evaluates organizations from perspective of business and trade factors. Khanzadeh (2007) considered the business intelligence as a comprehensive knowledge in terms of all factors such as customers, society and audiences, clientele and rivals, economic environment, organizational operations and processes, which influence the organization and enable managers for making appropriate decisions on all factors influencing organizations. It should be noted that business intelligence evaluates organizations, irrespective of business activity, in terms of all perspectives and organizational aspects. Some scientists have studied business intelligence from epistemological point of view: 
Cognitive, behavioral and social-emotional perspectives are important business intelligences. The primary objective is to understand how various schools of thought can offer a comprehensive insight of organizational intelligence in management and organizational development literature. The organizational intelligence is a social process where its underlying theories has been based on shear personal intelligence theories and have so far been neglected. The use of personal intelligence could not disclose social nature of organizational intelligence in turn.

Table 1

Definitions of Organizational Intelligence

\begin{tabular}{ll}
\hline Researcher & Definitions \\
Matsuda & Matsuda (Hayati, 2006) describes OI as collection of mental capabilities of an organization, which \\
& is a combination of two factors including human intelligence and machine intelligence. He \\
& explains that organizational intelligence consists of two components: As a process, organizational \\
& intelligence includes theoretical analysis of a firm with a collection of secondary processes and \\
& incorporates interactive features, consensus, cooperation or collaboration. As a product, \\
& organizational intelligence includes a mixed policy, plan and guidance for designing information \\
& system for firms. Of course, these two components have some overlap on each other and operate \\
& as two dependent factors on firms. \\
William Halal & Halal describes OI as the capacity of a firm for creating knowledge and using it for adaptation \\
& with the environment or market in strategic terms. The organizational intelligence is very close to \\
& Intelligence Quotient (IQ) but has been formed in an organizational level called Organizational \\
& Intelligence Quotient (OIQ) and similar to IQ, OIQ is measurable (Liebowitz, 2000). \\
& McMaster (1996) believes that OI is the ability of a firm and plays a leading role in increasing \\
McMaster & information, public knowledge innovation, OI is the primary source for the future that we require \\
& to think, manage and reorganize differently. \\
& According to Albrecht (2002), OI has seven dimensions: 1- Strategic Vision, 2- Shared Fate, 3- \\
Appetite for Change, 4- Alignment and Congruence, 5- Spirit, 6- Knowledge Deployment and 7- \\
Performance Pressure.
\end{tabular}

The seven dimensions, provided by Albrecht (2002) are considered as criteria in this study as follows:

\section{Strategic Vision}

Strategic vision is the capability for creation, inference and explanation of objectives of an organization. The leaders of the organizations must be able to respond these types of questions. Who are we? What is the philosophy of our nature? Why the world should accept us, be thankful to us and why the world should give us a reward for what we do?

\section{Shared Fate}

When all or most individuals are involved in working with an organization, they must understand that the mission and the organization's objectives, feel shared objective and every individual understand success of the organization.

\section{Appetite for Change}

In some organizational cultures guided by their founding construction teams, any type of change and development indicates a kind of weakness and possible chaos. In other circumstances, change indicates challenge, new business, another chance for start of new work and activity.

\section{Alignment and Congruence}

Without existence of a series of necessary regulations for execution, each group will face frequent problems and difficulties to continue work. The individuals and teams should organize themselves to materialize mission and objective of the organization. They also need to determine responsibilities, which should impose a series of rules for themselves. In an intelligent organization, systems, in a general definition, should prepare necessary ground for individuals in order to conduct their duties. 
"spirit" is normally formed in people's mind with accuracy and contemplation on the working life quality of personnel, feeling of staff on the work and management and degree of their optimism to their hob responsibilities and creating opportunities within the firm. For example, tendency of employee in distributing a thing beyond the expectation is a sample of high spirit. Therefore, they must distinguish their success based on the success of the organization and want to complete the activity, successfully.

\section{Knowledge Deployment}

Each organization's activities depends solely on the nature of information and knowledge, instant correct decisions, judgment, vigilance, shared meritocracy feeling of individuals and authenticity of used information, which is merged with the structure of the firm at every moment.

\section{Performance Pressure}

It is not sufficient to involve in performance in terms of materialization of indefinite strategic objectives and its results. In an intelligent organization, all managers should stand in their executive position.

\subsection{Competitive Advantage}

The theory of competitive advantage is one of the modern theories, introduced by Porter (1989). Accordingly, neither comparative advantage nor Hecksher-Ohlin Model can explain a suitable method for using innovation and creativity in production of goods and services. According to Porter (1989), "Competitive Advantage Theory of Nations", which is dependent on the capacity of innovation, creativity, initiative of countries, can explain the current conditions. Basically, the history of this theory dates back to 1950s in Harvard University and accordingly, the name of this university is known to the Harvard School.

\subsection{Value Chain}

According to Porter (1989), the activities involved in the manufacturing organizations can be divided into two parts of main and supportive. The first one, main activities, include Inbound Logistics, Manufacturing Operations, Outbound Logistics, Marketing and Sales, After-Sales Services while the second one, supportive activities, include organizational infrastructures including accounting, financial, management, human resources management, research and development (R\&D) and procurement and logistics. The value chain is described as a set of value-creating activities in interval of converting a concept and idea into a product or presentable service to final consumer through various stages of designing, producing, marketing, selling and sometimes recycling.

\subsection{Research Conceptual Model}

In this section, we explain conceptual model of the research and its components. The independent variables of organizational intelligence dimensions includes 1- strategic vision, 2- shared fate, 3appetite for change, 4- alignment and congruence, 5- spirit, 6- knowledge deployment and 7performance pressure in general while components of each of the activities are in particular. Indicators of research variables have been demonstrated in Fig. 1. In this model, we have studied the effects of OI activities in different sectors of value chain. The dependent variables in this research include development of professional skills of staff, innovation in products and services, market development of products and services and improvement of relations with customers. 
OI dimensions

Strategic vision
Shared fate
Appetite for change
Spirit
Knowledge development
Performance pressure

Factors of strategy of differentiation

Development of professional skills of staff

Innovation in product and services

Products and services market development

Improvement of relations with customers

Fig.1. Value Chain of Organization's Activities

\subsection{Dimensions and Components of Organizational Intelligence}

For measuring the impact of organizational intelligence on various sectors of value chain, we have to extract OI components according to each dimension. After exploratory studies and a review of research literature, dimensions and components of the OIs summarized in Table 3.

Table 3

Index of Dimensions

\begin{tabular}{|c|c|c|c|}
\hline Concept & Dimensions & \multicolumn{2}{|r|}{ Component / Index } \\
\hline \multirow{21}{*}{$\begin{array}{l}\text { Organizational } \\
\text { Intelligence }\end{array}$} & \multirow{3}{*}{ Strategic Vision } & 1 & Presenting new product (colors with new and distinctive designs and properties) \\
\hline & & 2 & Producing a part of required raw materials \\
\hline & & 3 & Exports of color \\
\hline & \multirow{3}{*}{ Shared Fate } & 4 & To avoid wasting time and maximize production \\
\hline & & 5 & Increasing its profitability and sustainability \\
\hline & & 6 & To avoid wasting raw materials and energy \\
\hline & Appetite for Change & 7 & Having the spirit of diversity and creativity in different parts \\
\hline & \multirow{3}{*}{$\begin{array}{l}\text { Alignment and } \\
\text { Congruence }\end{array}$} & 8 & Helping other units to accelerate progress of activities \\
\hline & & 9 & Organizing meetings and consultations to make decisions in different units \\
\hline & & 10 & Cooperation of production and laboratory unit to improve quality of colors \\
\hline & \multirow[b]{3}{*}{ Spirit } & 11 & Cooperating aimed at promoting objectives of company \\
\hline & & 12 & Creating a customer-oriented spirit \\
\hline & & 13 & Resisting against problems \\
\hline & \multirow{5}{*}{$\begin{array}{l}\text { Knowledge } \\
\text { Deployment }\end{array}$} & 14 & Using new production devices and modern methods of producing powder coating \\
\hline & & 15 & Use of new raw materials with better quality and more functionality \\
\hline & & 16 & Reformulation of colors in order to reduce cost and increase quality \\
\hline & & 17 & $\begin{array}{l}\text { Using new methods of packaging and warehousing to increase customers' satisfaction } \\
\text { and capability of exports }\end{array}$ \\
\hline & & 18 & Using modern methods of marketing in order to penetrate new markets \\
\hline & \multirow{3}{*}{$\begin{array}{l}\text { Performance } \\
\text { Pressure }\end{array}$} & 19 & Increasing production efficiency and reducing delivery time \\
\hline & & 20 & Increasing product quality and establishing diversity and innovation \\
\hline & & 21 & Penetrating new markets to achieve sustainable competitive advantage \\
\hline
\end{tabular}

\subsection{Statistical and Research Methodology}

After obtaining management viewpoints through interviews and formulating hypotheses for evaluating their validity, these hypotheses were tested through sending questionnaires to the companies, which are active in powder coating production industry. The companies active in powder coating production industry were the subject of this study. The main activity of these companies is as follows: producing various types of powder coating paints with polyester-based resin, hybrid and polyurethane. The variety of products includes different types of simple, leather, hammer, sandpaper, wrinkle and metallic colors. Electro Zar Sazeh Company, which is regarded as one of the subjects of 
this study, succeeded in devising a new plan of powder coating named "Turk Paint" in 2011. To date, the said color is considered as exclusive color of this company.

The powder paints are mostly used in steel furniture, metallic fittings, home appliances, auto parts, equipment and machinery and aluminum foils, etc.

The research questionnaire was sent to 20 companies and 12 questionnaires were received from senior managers, 15 questionnaires from human resources managers, 17 questionnaires from sales and marketing managers and 16 questionnaires from research and development (R\&D) managers. The return rate of questionnaires stands at $75 \%$, which indicates that these managers have cooperated properly with the mentioned organizations in this respect.

The tool used in this study is of closed-type questionnaire. Questionnaire of viewpoints of managers on the role of organizational intelligence in various sectors of the organization, questionnaire of measuring professional skills of staff, questionnaire of measuring customers' satisfaction and questionnaire of measuring innovation are of the tool type made by the researcher.

Albrecht (2003) Organizational Intelligence Questionnaire was used in order to measure organizational intelligence. According to the Cronbach's Alpha Coefficient, reliability of organizational intelligence was obtained $0.79,0.804,0.776,0.81,0.913,0.769$ and 0.845 for strategic vision, shared fate, appetite for change, alignment and congruence, spirit, knowledge deployment and performance pressure respectively.

\section{Analysis of Research Results}

Chi-square test was used in order to study presence or absence of concepts and dimensions of organizational intelligence from respondents' view. If, according to the obtained results, Ho is accepted, it means that provided answers to the dimension enjoy uniform distribution, but if Ho is rejected, it is concluded that the provided answers do not enjoy uniform distribution and would be based on the observed frequency bias for or against the options.

\section{Decision-Making Rule}

In $95 \%$ confidence number, if significant number is larger than the error rate $(0.05), \mathrm{H}_{0}$ is accepted. However, if significant number is smaller than the error ate $(0.05), \mathrm{H}_{1}$ is accepted.

Devising Null and One Hypothesis

$\mathrm{H}_{0}$ : Null Hypothesis: The provided responses enjoy uniform distribution.

$\mathrm{H}_{1}$ : Opposite Hypothesis: Provided responses do not enjoy uniform distribution.

\section{Table 4}

Results of Organization intelligence in Products and Services Development from Viewpoint of Top Managers

\begin{tabular}{|c|c|c|c|c|c|c|c|c|c|}
\hline \multirow[t]{2}{*}{ No. } & \multirow{2}{*}{$\begin{array}{l}\text { Organizational intelligence } \\
\text { dimensions }\end{array}$} & \multicolumn{4}{|c|}{ Observed Frequencies } & \multirow[b]{2}{*}{$\mathrm{X}^{2}$} & \multirow[b]{2}{*}{ Sig. } & \multirow[b]{2}{*}{$\begin{array}{l}\text { Error } \\
\text { rate }\end{array}$} & \multirow[b]{2}{*}{ Null hyp. } \\
\hline & & Low & $\begin{array}{l}\text { Less than } \\
\text { average }\end{array}$ & $\begin{array}{l}\text { More than } \\
\text { Average }\end{array}$ & High & & & & \\
\hline 1 & Strategic visions & 0 & 1 & 2 & 9 & 16.66 & 0.001 & 0.05 & Rejected \\
\hline 2 & Shared fate & 1 & 2 & 3 & 6 & 4.667 & 0.198 & 0.05 & Not rejected \\
\hline 3 & Appetite for change & 1 & 1 & 2 & 8 & 11.33 & 0.010 & 0.05 & Rejected \\
\hline 4 & Alignment and congruence & 0 & 2 & 3 & 7 & 8.667 & 0.034 & 0.05 & Rejected \\
\hline 5 & Spirit & 0 & 2 & 3 & 4 & 12.66 & 0.005 & 0.05 & Rejected \\
\hline 6 & Knowledge deployment & 1 & 1 & 2 & 8 & 11.33 & 0.010 & 0.05 & Rejected \\
\hline 7 & Performance pressure & 0 & 2 & 2 & 8 & 12.00 & 0.007 & 0.05 & Rejected \\
\hline
\end{tabular}


Table 5

Results of effect of organizational intelligence in development of products and services market share from viewpoints of sales and marketing managers

\begin{tabular}{|c|c|c|c|c|c|c|c|c|c|}
\hline \multirow[t]{2}{*}{ No. } & \multirow{2}{*}{$\begin{array}{l}\text { Organizational intelligence } \\
\text { dimensions }\end{array}$} & \multicolumn{4}{|c|}{ Observed Frequencies } & \multirow[b]{2}{*}{$X^{2}$} & \multirow[b]{2}{*}{ Sig. } & \multirow[b]{2}{*}{$\begin{array}{l}\text { Error } \\
\text { rate }\end{array}$} & \multirow[b]{2}{*}{ Null hyp. } \\
\hline & & Low & $\begin{array}{c}\text { Less than } \\
\text { average }\end{array}$ & $\begin{array}{l}\text { More than } \\
\text { Average }\end{array}$ & High & & & & \\
\hline 1 & Strategic visions & 1 & 2 & 5 & 9 & 9.118 & .028 & 0.05 & Rejected \\
\hline 2 & Shared fate & 2 & 3 & 4 & 8 & 4.88 & 0.181 & 0.05 & Not rejected \\
\hline 3 & Appetite for change & 0 & 2 & 7 & 8 & 10.529 & .015 & 0.05 & Rejected \\
\hline 4 & Alignment and congruence & 1 & 2 & 4 & 10 & 11.471 & .009 & 0.05 & Rejected \\
\hline 5 & Spirit & 0 & 2 & 5 & 10 & 13.353 & .004 & 0.05 & Rejected \\
\hline 6 & Knowledge deployment & 1 & 1 & 6 & 9 & 11.000 & .012 & 0.05 & Rejected \\
\hline 7 & Performance pressure & 1 & 1 & 4 & 11 & 15.706 & .001 & 0.05 & Rejected \\
\hline
\end{tabular}

Table 6

Results of effect of organizational intelligence in promoting professional skills of manpower from viewpoints of human resources managers

\begin{tabular}{|c|c|c|c|c|c|c|c|c|c|c|}
\hline \multirow[t]{2}{*}{ No. } & \multirow{2}{*}{$\begin{array}{l}\text { Organizational intelligence } \\
\text { dimensions }\end{array}$} & \multicolumn{5}{|c|}{ Observed Frequencies } & \multirow{2}{*}{$X^{2}$} & \multirow[b]{2}{*}{ Sig. } & \multirow[b]{2}{*}{$\begin{array}{l}\text { Error } \\
\text { rate }\end{array}$} & \multirow{2}{*}{ Null hyp. } \\
\hline & & Low & $\begin{array}{l}\text { Less than } \\
\text { average }\end{array}$ & & $\begin{array}{l}\text { More than } \\
\text { Average }\end{array}$ & High & & & & \\
\hline 1 & Strategic visions & 0 & 2 & 4 & & 9 & 11.933 & .008 & 0.05 & Rejected \\
\hline 2 & Shared fate & 0 & 3 & 4 & & 8 & 8.733 & .033 & 0.05 & Rejected \\
\hline 3 & Appetite for change & 0 & 2 & 6 & & 7 & 8.733 & .033 & 0.05 & Rejected \\
\hline 4 & Alignment and congruence & 1 & 2 & 3 & & 9 & 10.333 & .016 & 0.05 & Rejected \\
\hline 5 & Spirit & 0 & 2 & 4 & & 9 & 11.933 & .008 & 0.05 & Rejected \\
\hline 6 & Knowledge deployment & 1 & 1 & 5 & & 8 & 9.267 & .026 & 0.05 & Rejected \\
\hline 7 & Performance pressure & 1 & 1 & 3 & & 10 & 14.600 & .002 & 0.05 & Rejected \\
\hline
\end{tabular}

\section{Table 7}

Results of effect of organizational intelligence in improving relations with customers from viewpoints of R\&D managers

\begin{tabular}{|c|c|c|c|c|c|c|c|c|c|}
\hline \multirow[t]{2}{*}{ No. } & \multirow{2}{*}{$\begin{array}{l}\text { Organizational intelligence } \\
\text { dimensions }\end{array}$} & \multicolumn{4}{|c|}{ Observed Frequencies } & \multirow[b]{2}{*}{$X^{2}$} & \multirow[b]{2}{*}{ Sig. } & \multirow[b]{2}{*}{$\begin{array}{l}\text { Error } \\
\text { rate }\end{array}$} & \multirow[b]{2}{*}{ Null hyp. } \\
\hline & & Low & $\begin{array}{l}\text { Less than } \\
\text { average }\end{array}$ & $\begin{array}{l}\text { More than } \\
\text { Average }\end{array}$ & High & & & & \\
\hline 1 & Strategic visions & 1 & 1 & 4 & 10 & 13.500 & .004 & 1 & Rejected \\
\hline 2 & Shared fate & 2 & 2 & 4 & 8 & 6.00 & 0.112 & 2 & Rejected \\
\hline 3 & Appetite for change & 0 & 2 & 6 & 8 & 10.000 & .019 & 0 & Rejected \\
\hline 4 & Alignment and congruence & 1 & 2 & 4 & 9 & 9.500 & .023 & 1 & Rejected \\
\hline 5 & Spirit & 0 & 2 & 4 & 10 & 14.000 & .003 & 0 & Rejected \\
\hline 6 & Knowledge deployment & 0 & 2 & 6 & 8 & 10.000 & .019 & 0 & Rejected \\
\hline 7 & Performance pressure & 1 & 1 & 3 & 11 & 13.500 & .004 & 1 & Rejected \\
\hline
\end{tabular}

\section{Conclusion}

Organizational intelligence helps firms create diversity in financial resources, analyze programs and performances, develop visions, redefine missions and design appropriate strategies. As talent and capacity of an organization, $\mathrm{OI}$ is defined to create mental power and to focus on this mental power in materializing mission of the organization. Finally, managers of the organizations should consider OI. These managers should reevaluate step by step dimensions of OI implementation in their organizations. The issue promotes OI subsystems required for being turned into an organization with high organizational intelligence. In this paper, we have studied the results OI implementation in some organizations. For the comprehensive analysis of effects of using organizational intelligence, we need to consider organization and all its sectors with a comprehensive view. In addition, effects of OI processes should be studied on various sectors of the organization. With due observance to the this effect, we have embarked on evaluating these effects through using Porter Value Chain which 
considers all parts of the organization in its success with a compressive view. In the same direction, we have used Albrecht's model in organizational intelligence issue, which has seven dimensions. In the course of research, we first embarked on formulating hypotheses with conducting exploratory studies such as review of literature and holing interviews. The results confirmed validity of research hypotheses. The results of this study indicated that organizations, if use organizational intelligence strategy systematically, could enjoy competitive advantage in various sectors of their value chain, details of which can be used in the arena of competition.

\section{Acknowledgment}

The author would like to thank the anonymous referees for constructive comments on earlier version of this work.

\section{References}

Albrecht, K. (2002). Organizational intelligence and knowledge management: Thinking outside the silos.

Albrecht, K. (2003). The power of minds at work: Organizational intelligence in action. amazon, New York.

Akgün, A.E., Byrne, J., \& Keskin, H. (2007). Organizational intelligence: a structuration view. Journal of Organizational Change Management, 20(3), 272-289.

Alvani, S.M., \& Danaeifar, H. (1997). Qualitative Methodology in Management, 153-166, Tehran, SAFAR Publications

Ganji, H. (2003). General Psychology, Tehran, Savalan Publication (In Farsi . (

Hafeznia, M.R. (1997), An Introduction to Methodology in Humanities, 1974-1979, Tehran, SAMT Publications (In Farsi . (

Liebowitz, J. (2000). Building Organizational Intelligence: A Knowledge Management Primer, CRC Press, ISBN 0-849-32036-4

Munn, N.L. (1956). Psychology: The fundamentals of human adjustment. Houghton Mifflin, 3rd ed .

McMaster, M. D. (1996). The intelligence advantage: organizing for complexity. ButterworthHeinemann, Boston .

Porter, M.E. (1989). How competitive forces shape strategy. Harvard Business Review, 57(2), 137 145.

Yolles, M. (2005). Organisational intelligence. Journal of Workplace Learning, 17(1/2), 99 - 114 .

Teo, T.S.H., \& Men, B. (2008). Knowledge portals in Chinese consulting firms: a task-technology fit perspective. European Journal of Information Systems, 17(6), 557-74.

Quigley, N.R., Tesluk, P.E., Locke, E.A., \& Bartol, K.M. (2007). A multilevel investigation of the motivational mechanisms underlying knowledge sharing and performance. Organization Science, 18(1), 71-88

Wasko, M.M., \& Faraj, S. (2005). Why should I share? Examining social capital and knowledge contribution in electronic networks of practice. MIS Quarterly, 29(1), 35-57.

Wu, J.-H., \& Wang, Y.-M. (2006). Measuring KMS success: a respecification of the Delone and Mclean's model. Information \& Management, 43(6), 728-39. 